\title{
What is a mode account of collective intentionality?
}

\author{
Michael Schmitz \\ (Penultimate draft; final version published in Gerhard Preyer \& Georg Peter (eds.), Social \\ Ontology and Collective Intentionality: Critical Essays on the Philosophy of Raimo Tuomela \\ with his Responses; Springer 2017, pp. 37-70; please refer to the published version.)
}

\section{Mode vs. content and subject approaches to collective intentionality}

Many attempts to understand collective intentionality have tried to steer between two extremes. We want to understand how the members of a group are bound together, what turns them into a group, so we don't want to think of the group as a mere sum of individuals. At the same time, we don't want the group to be free-floating with regard to the members. It should not come out as just another individual, as an additional person as it were, nor should it be emergent in a radical sense. It's useful to distinguish attempts to accomplish this balancing act in terms of where they solely or predominantly locate collectivity: in the content of relevant intentional states (or speech acts), in their mode, or in their subject(s) (Schweikard and Schmid 2012). A content approach tries to understand collectivity in terms of the contents of the subjects' intentionality, where content is understood in the standard fashion, namely as what the subjects believe, intend, hope, feel, and so on. So on this kind of view, collectivity is just a matter of certain kinds of things that individuals believe, intend, and feel with regard to each other. On this perspective, the bestknown representative of which is Michael Bratman (1992; 2014), there may be a 'we' of joint action as represented in the content of intentions, but these intentions are always of the form ' $I$ intend that we J', so that no collective 'we'-subject of intentional states is represented. ${ }^{1}$ Now, this kind of approach is in danger of erring on the side of being too individualistic. Can we really 
reduce all our practical and theoretical we-thoughts to I-thoughts? Does it make sense to suppose that an individual subject intends a collective action? On the other side of the spectrum, we find those who unabashedly embrace the notion of collective, plural subjects (Gilbert 1992; Schmid 2009) and thus, many will feel, put themselves in danger of erring on the side of being too collectivistic. What can it mean that there is an additional subject here? Do we really have to commit to such an entity just in order to explain joint action?

It is easy to sympathize with attempts that try to find a middle ground between these approaches. A clear statement of such an alternative is provided by John Searle $(1995 ; 2010)$. Searle holds that we-intentionality is conceptually irreducible to I-intentionality, but that this form of intentionality can be entirely located in the minds (and heads) of individuals, and that these individuals - and only these individuals - are the logical subjects of this intentionality. So Searle rejects both conceptual reduction as well as ontologically irreducible collective subjects. His attitude could be summed up in the slogan "Conceptual reduction no, ontological reduction yes!". Searle does not himself use the term "we-mode", but his account can be classified as a wemode approach (Salice 2014; Wilby 2012), and is easily stated in the we-mode terminology: wemode states are irreducible to I-mode states, but the subjects of such states are individuals and individuals alone.

It is to Raimo Tuomela, however, that we owe the most comprehensive, detailed and elaborate version of a we-mode account (e.g. 1995; 2002; Tuomela 2007). Tuomela pioneered the we-mode approach, drawing on some seminal ideas from Wilfrid Sellars, who appears to have been the first to use the term "we-mode". ${ }^{2}$ Tuomela has made it the core notion of his account of collective intentionality, which he has developed over several decades, culminating in his most mature and accessible presentation yet in his recent book "Social Ontology. Collective Intentionality and Group Agents" (2013a). His account is complex and defies easy summary. But he is clearly also trying to steer a middle course between the Scylla of excessive individualism and the Charybdis of extreme collectivism:

\footnotetext{
${ }^{1}$ It should be noted that Bratman restricts his claim to what he calls ,modest sociality“, planning agency in small-scale groups.

${ }^{2}$ See (Sellars 1963, 205). For some of the earlier history see e.g. (Tuomela 2013b)
} 
The weak conceptual and epistemic collectivism of this book may accordingly be seen as defending a common-sense alternative that lies somewhere between the extreme groupcenteredness of German Idealism and the conceptually impoverished framework of rational choice theory as we now have it. (4)

Tuomela holds that a reduction to descriptions of individual behavior is not "instrumentally feasible" (2) and that a conceptual reduction of the we-mode is even impossible. At the same time he takes a cautious attitude towards the ontology of groups and particular that of group agents, characterizing them as socially constructed (22), even fictitious (47) and their intentionality as derived rather than intrinsic (3). On the positive side, he explains the we-mode in terms of group reasons, in terms of the collectivity condition - basically that we are all in the same boat as regarding the successes (and failures) of the group - and in terms of notions of collective commitments and of the obligations of group members and the ethos of the group.

I applaud the ambition of the we-mode approach to find a middle ground between extreme forms of individualism and collectivism. I find talk of 'mode' suggestive and intuitively compelling as way of bringing out that those engaged in collective endeavors are in a special state of mind. And Tuomela demonstrates how the notion of 'we-mode' can be theoretically fruitful in his framework. In particular, he uses it beautifully to show how traditional puzzles of game-theoretic rationality such as the prisoner's dilemma and the Hi-Lo-game can be dissolved if the we-perspective is taken seriously (see ch. 7 and Hakli, Miller, and Tuomela 2010). He is, I think, also right to give the notion of a group reason a central place in his account of the wemode. And there are many more convincing applications of his theoretical apparatus in the book that I can't even begin to discuss here. At the same time, there is a fundamental question about the we-mode that I think does not receive a clear answer in Tuomela's account. At other points, I find it irresistible to take the notion of mode further, to develop it beyond the confines of Tuomela's theory - but still very much in the spirit of his approach. Finally, I believe that Tuomela's account, like almost all current thinking about collective intentionality and even about mind and language generally, is unnecessarily restricted by the confines of the traditional understanding of the notion of a 'propositional attitude'. After thinking about issues of collective intentionality and about mode more generally for many years, I have come to the conclusion that this notion is biased in several ways and needs to be revised quite fundamentally. So what I want 
to do in this paper is to pose some questions about Tuomela's account of the we-mode and the notion of mode in general, and then go on to suggest that they are best answered by rethinking mode and 'propositional attitudes' along the lines I will sketch.

\section{What is the we-mode and when?}

What exactly is the we-mode, and how is it manifest in the mind? What does it mean, for example, that the members of a group are in the we-mode at a certain point in time? This fundamental question is not yet answered by appealing to the collectivity condition, to group reasons, or other elements of Tuomela's theoretical apparatus as such, because this does not tell us how these elements are manifest in the mind at a given time. ${ }^{3}$ One answer we find in SOCIAGA is as follows:

...to think (e.g., have an attitude) and act in the we-mode is to think and act fully as a group member. This represents a mode of thinking and acting, to act we-modely, to express it adverbially. Thus, e.g., attitudes can be in the we-mode or in the I-mode, and this concerns the respective mode of having them or, in the important collective case, of sharing them. As such the mode can be conceptually separated from the attitude content. (37)

The positive answer here is that mode can be understood adverbially: we think and act wemodely. The negative answer, which appears to reinforce the distinction between mode and content accounts of collective intentionality, is that mode can be separated from content - where content is representational / intentional content in the way it is usually conceived, namely as what is believed, intended, and so on: as the so-called propositional content of a propositional attitude. However, the positive answer, while suggestive, cannot really answer the question on its own, but just pushes it further: what does it mean to act and think we-modely? The only thing that does seem clear is that this must be in virtue of facts about the mind.

Two suggestions which are worth mentioning for purposes of clarification, if only to set them aside, are the following. First, being in the we-mode might be a matter of phenomenal, but

\footnotetext{
${ }^{3}$ For a lucid discussion of another fundamental question about the we-mode, namely in which sense if any it is a mode in the same sense in which e.g. intending and believing are modes, see Bernhard Schmid's contribution to this issue.
} 
non-intentional content. It is certainly plausible that affects and emotions are very important for group membership, so if one takes a non-representationalist view of them, one might say that certain feelings are what makes thinking and acting we-modely what it is. On the opposite side of the spectrum, it might be suggested that acting and thinking we-modely is solely a matter of a distinct causal role. However, if there were no differences in phenomenal and / or intentional content connected with this causal role, it's hard to see how this could count as a mental difference. Moreover, though Tuomela often and rightly emphasizes the distinct causal role of groups and the we-mode, there is no indication that he wants to dissociate it from intentional content. Nor is there any textual evidence that he wants to understand the we-mode in purely phenomenal terms.

We will later return to the role of affect in collective intentionality. But for now it seems that our question how the we-mode is manifest in the minds of group members is surprisingly hard to answer in a straightforward way. Having set aside some theoretically possible ideas, here's the best suggestion that I can think of that is consistent with the letter and spirit of what Tuomela says. First, let me note that the core analyses that Tuomela gives, for example, in the collectivity condition, are in terms of what group members intend and believe and thus in terms of content (see ch. 2). Second, we might think of what the we-mode does in terms of making these contents easily accessible or salient or something along these lines. That is, the functional role of the we-mode would be in terms of dispositions for intentional states to become manifest in consciousness, or in terms of their salience in consciousness, or any combination of the two, or perhaps further functional properties. However, if this line is taken, the we-mode approach collapses into the content approach. Dispositions in virtue of content should be classified on the content side, as dispositions in general are classified in terms of what they are dispositions for: musical abilities, for example, are musical because they issue in musical performances. ${ }^{4}$ Or we would have to return to the view that the we-mode is solely a matter of functional role without being manifest in either intentional or phenomenal content.

One hint that the content line might still be the direction in which Tuomela is thinking but it is really only a hint - is that he says, in the passage quoted above, that mode can be “conceptually separated" (ibid., my emphasis) from content. While, as we noted, at first this seems to reinforce the difference between content and mode approaches, Tuomela may yet mean 
that, while the concept of we-mode is not the concept of certain intentional states with certain contents - at least not initially - ultimately it can still be fully explained in terms of such contents and corresponding dispositions, because there is really nothing more there ontologically. Moreover, this interpretation also makes good sense of the adverbial aspect of Tuomela's proposal. Being in the we-mode would be a matter of (generally) being in certain intentional states with certain contents, such as those specified in the collectivity condition and other parts of Tuomela's analysis, and of how likely such states are to become manifest in consciousness and what degree of prominence they are likely to reach within consciousness. The latter dispositional properties would account for what it means to act and think we-modely at a given point or during a given period in time. I would be in the we-mode when I am more likely to think of elements of the group ethos, of my obligations to the group, the fact that I and the other group members are in the same boat, and so on, and such thoughts have greater prominence in my consciousness than at other times. ${ }^{5}$

\section{We-mode and the ontology of groups and group agents}

The interpretation given is also consistent with the ontological picture of groups and particularly of group agents given in SOCIAGA. In the book, Tuomela generally operates with a tri-partite distinction between group-relevant intentional states as ascribed to individual group members (e.g., we-intentions), to individual group members jointly (e.g., joint intentions), and to groups organized for action (e.g. the intentions of group agents; see especially ch. 3 for these distinctions). Though Tuomela also seems to allow that there is a sense in which all we-mode groups are group agents, the paradigm cases for this category include corporations such as Apple or political entities like the government of France. With regard to such actors, the temptation to think that they are free-floating relative to the relevant individuals is particularly strong, as they retain their identity through constant and thorough changes of personnel. SOCIAGA employs several different strategies to argue that reference to groups and group agents is both necessary and harmless and non-mysterious. As we have noted already, Tuomela points out that reductions of descriptions of group behavior to individual intentional behavior are "not instrumentally

\footnotetext{
${ }^{4}$ For a discussion of this in the context of Searle's notion of the background, see my (2012).
} 
feasible" (2). He even says that they "probably cannot be carried out either for more general theoretical reasons" (2) and goes on to state:

The ultimate social scientific framework must allow individuals to make reference to social groups - conjectured to be individualistically irreducible - in the contents of their mental states. ... we may even go further and accord to social groups a functional and intentional existence as social systems (2; my emphasis)

This supports the interpretation that the crucial reference to groups occurs in the content (as traditionally conceived) of intentional states. The idea of the "functional and intentional existence" of groups is further explained as follows:

... a group organized for action is regarded as an agent from a conceptual and justificatory point of view, although in the causal realm it exists only as a functional social system capable of producing uniform action through its members' intentional action. A group agent in the sense of this book is not an intrinsically intentional agent with raw feels and qualia, as contrasted with ordinary embodied human agents. The functional and intentional existence of the group is extrinsic and basically derives from the joint attitudes, dispositions and actions of its members, and from the irreducible reference to the group that these attitudes and actions involve and that is here assumed to make groups conceptually irreducible to the members' individual properties and relationships not based on the group. (3; my emphases)

The central and new argument in SOCIAGA for conceptual irreducibility turns on the irreducibility of we-mode reasons: "reducibility fails because we-mode reasoning leads to a set of action equilibria different from what individualist, I-mode theorizing leads to" (11). This is true even in comparison with pro-group attitudes in the I-mode. ${ }^{6}$ An example is a Hi-Lo game:

\footnotetext{
${ }^{5}$ Those who believe that mental states can become occurrent other than by becoming conscious can reformulate this explication accordingly. For some thoughts on the relation between mind and consciousness, see my (2012).

${ }^{6}$ For the notion of the pro-group I-mode, see p. 37. Tuomela also holds that there can be wethinking in the I-mode and conversely. For ease of exposition, I defer discussion of these complexities until the end of this paper.
} 


$\begin{array}{lll} & \text { Hi } & \text { Lo } \\ \text { Hi } & 3,3 & 0,0 \\ \text { Lo } & 0,0 & 1,1\end{array}$

In this familiar coordination game without communication, it is obvious from a we-perspective that a rational group should choose $\mathrm{HiHi}$ and get the highest payoff, while classical game theory, from its purely individualistic perspective "cannot recommend HiHi over LoLo (or indeed anything at all)" according to SOCIAGA (11; see ch. 7 for the fully developed argument).

But even though SOCIAGA thus argues for a not merely instrumental, but also conceptual irreducibility of group agents, the passage quoted above at the same time reveals that it does not embrace an unabashed realism about collective subjects either. The group is regarded as an agent from a conceptual and justificatory, but not from a causal and ontological point of view; the group agent's intentionality is not intrinsic, but merely extrinsic and derived from the intentionality of its members; it does not have "raw feels and qualia"; and groups also cannot be "full-blown agents (or persons) in the flesh-and-blood sense" (23). Now of course Tuomela is here just registering that he rejects the collectivistic Charybdis that everybody wants to avoid, viz. the idea that the group is just like another person. But it is important that he feels he therefore needs to reject the idea that a group can be the subject of intrinsically intentional and conscious states that are causally efficacious. One key question of this paper is whether this is really necessary.

Tuomela moves further towards a kind of fictionalism when he says that a group agent is "based on its members regarding and constructing it as a group agent" (22) and explicitly embraces it in passage like the following:

What does it mean to say that a group agent is fictitious and has fictitious features? My view is that group agents are mind-dependent entities and fictitious in the mind-dependence sense that involves collective imagination, idealization, and construction. They do not exist as fully intentional agents except perhaps in the minds of people (especially group members). This also makes the intentional states attributed to them fictitious because the bearers (viz., group agents) of these states are fictitious (not real except in the minds of the group members). That a group's 
intention or belief, etc., is fictitious entails that it is not literally true that it intends or believes, etc.. (47)

So while group agents and their intentional states are conceptually irreducible, they still are not ontologically real - except "perhaps" in the minds of people, especially group members. They are just fictions, mental constructions. However, there is an already noted qualification to that, which I want to emphasize once more because it is so important:

Only the intentional properties attributed to groups are fictitious in the mere mind-dependence sense. Group agents qua nonintentional systems have causal powers and are capable of causing outcomes in the real world. (47)

In this way Tuomela wants to reconcile his version of fictionalism with his insistence that being in the we-mode does make a functional, causal difference. For example, people in the we-mode will behave differently in the Hi-Lo game or the prisoner's dilemma than people in the I-mode, even in the pro-group I-mode. This seems like mere common sense and is confirmed by first empirical investigations into these issues (e.g. Colman, Pulford, and Rose 2008). And if it wasn't the case, the notion of a group agent would lose the "explanatory, predictive, and descriptive usefulness" (46; emphases in the original) SOCIAGA plausibly ascribes to it. However, the price to be paid for this marriage of fictionalism and causal realism about group agents is that the relevant causation is not intentional causation (Searle 1983, chap. 4). That is, it is not a matter of, say, the group adopting an intention and this intention causing it to act in a certain way. The group agent and its intentional states can't cause anything qua intentionality because they are mere fictions on Tuomela's view, and because individuals are, as he likes to put it, "the only action-initiating "motors" in the social world" (5). So groups can only cause things qua nonintentional systems. Individuals are the only intentional causal agents, though an individual may act as a "representative" (15) for the group.

To summarize the ontological picture of group agents in SOCIAGA, they are irreducible in at least two senses. First, in an instrumental, pragmatic sense: it would not be feasible to give an account of sociality just in terms of individuals and their intentionality. Second, they are also conceptually irreducible because the we-mode perspective, for example in reasoning about the 
familiar game-theoretic puzzles, can't be conceptually reduced to the I-mode. At the same time, they are mere fictions. They are constructed as such by the group members, who represent them in the contents of their intentional states. They therefore also lack intrinsic intentionality and consciousness and only have extrinsic, derived intentionality. And they cannot cause anything qua intentional agents, but only as non-intentional systems. Ontologically, individuals are the only intentional causal agents. And again, this picture is consistent with the interpretation of the we-mode and its manifestation advanced earlier. The group agent is constructed in the contents of we-mode mental states, so that again it turns out that the contents do the crucial work. The causal difference between I-mode and we-mode is either explained by differences in content, or not grounded in any intentional differences at all.

\section{Some problems for the mode account of SOCIAGA}

Now, the account of the we-mode and the ontology of group agents that we have found in SOCIAGA is perfectly consistent, has some attractive features, and the fact that it seems to turn out to be a version of the content approach to collective intentionality after all can of course not be an argument against it as such. Still, in this paper I want to explore the possibility of an account that let's the mode approach come into its own more. This account also wants to understand mode in terms of content, but not in the standard sense of what subjects intend, believe, and so on, but in terms of a kind of content peculiar to mode - mode content respectively two types of such content: attitude or position mode content and subject mode content. I want to suggest that in taking up an intentional state or performing a speech act, a subject represents not only a state of affairs that it believes to obtain or intends to bring about, but also itself and its position or attitude of believing or intending etc. vis-à-vis that state of affairs. I will argue that this conception of mode as representational is the best way to account for a fundamental idea SOCIAGA also often appeals to: namely that the we-mode is based on wethinking and "we-reasoning from the group's point of view" (15; emphasis in the original). The subject mode account of collective intentionality that I want to explore here wants to understand the we-mode fundamentally in terms of the "we" representing a subject of joint attitudes towards states of affairs. Moreover, I also want to explore the idea that there are more kinds of subject mode than just the we-mode, namely a mode of jointly attending, which is more basic, and role 
mode(s), where we think and act in our capacities as the occupant of institutional roles such as being prime minister, which belong to a higher level of collective intentionality.

To motivate an investigation of these ideas, I now want to indicate certain areas where I think they could solve problems for SOCIAGA's version of the mode-approach. These problems can be distinguished in terms of whether they can be solved by acknowledging that mode is representational, or by recognizing different kinds of mode beyond the we-mode. I will then advance some doubts about the ontological picture and go on to suggest that the subject mode account may be also able to provide a better one.

Let me begin by raising a problem about the notion of reasons, which is of the first kind. Tuomela rightly gives group reasons an important place in his account of the we-mode. However, there is a tension between a strong emphasis on group reasons as being an essential aspect of mode and the idea that mode is distinct from (intentional) content. This is because how we usually understand reasons and reasoning, they certainly essentially involve content. For example, whether that it is raining is a reason to pick up an umbrella when going outside depends on the content of the corresponding belief and the contents of further desires, preferences and plans of the relevant subject. Similarly when, for example, the fact that it is raining is a reason for me as a group member to stay in the lodge - say as the member of a hiking expedition - but not as a private, I-mode person - say because most of my fellow hikers don't like hiking in the rain, while I do - it is easier to make sense of this difference between the reasons of a group and those had by one of its members as a private person, if we think of the difference between Imode and we-mode as being itself reflected in content, if we think of the position or perspective of the individual or collective subject vis-à-vis the relevant state of affairs as being itself represented. Or so I shall argue.

There is thus a problem about how to account for group-specific reasons and reasoning without group-specific, we-mode content. But there is also a problem about whether all collective intentionality involves reasons, as Tuomela's we-mode account in terms of group reasons suggests. Can joint attention and joint bodily action really be explained in terms of reasons and reasoning? Of course, joint action and attention can be informed by reasons and reasoning. After weighing the pros and cons, we may decide to go on a walk and take in the scenery together. But in the actual execution of this plan, lower-level mechanism of coordination, of alignment, attunement and synchronization - which have been extensively 
investigated empirically in recent decades - take over. And we may form or deepen a bond that is not rational - not irrational either, but arational. There is more to tie people together than reasons.

Similar remarks apply to the notion of commitment and to related deontological notions such as the notions of obligations, duties, or rights. Counter to what Margaret Gilbert suggested with her famous use of the example, I think we can go on a walk together without incurring obligations to one another. We may just meet on the way and start walking together, stopping for the other person and looking at the ocean or forest together, without ever jointly or individually committing ourselves to this action. We just do it. We could even evolve a pattern or habit of doing this, always meeting at about the same time and taking the same walk together. This would create expectations and most likely an emotional bond so that one of us would be disappointed if the other did not show up at all or just abandoned the joint walk at some point. But this still would not mean that we had committed to the joint action or had an obligation to one another. I think we should reserve these notions for cases where we actually communicate an intention to walk together, where we agree to go on a joint walk, or one promises this to the other.

A mere practice, pattern, or habit of walking together would however provide a good basis or background for such commitments. You might say to me that you can't come tomorrow, but that we should then walk together again on the following day, because you know that I will be disappointed if you just don't show up and because you want to communicate to me that you appreciate our walks together and want to continue. If we then agree to further walks and plan them together, we have, taken our practice of walking together and indeed our whole relationship to a new level - as one says - the level of joint plans, commitments and obligations. But this level, which is the level of the we-mode, can only be properly understood if we see that it just works against the background of more elementary forms of collective intentionality, of joint attention, joint bodily action and the kind of emotional bond that these typically involve. Or so I shall argue. These two last problems about the general application of the notion of reasons and of deontological notions are of the second kind, that is, they can be solved by recognizing lower level modes of collective intentionality like the mode of joint attention.

There is not only a level of collective intentionality below the level of the we-mode, but it can also be made plausible that there is (at least) one above it, namely that of elaborate institutions and, in particular, organizations. These are typically entities that have names or other 
kinds of designations, such that we can ascribe actions and intentional states to them in the singular and say things like "Facebook wants to raise its advertising revenue", or "The German ministry of finance rejected the Greek proposal". That is, they are group agents in Tuomela's sense. I believe that to understand institutional actors, at this level, require us to go beyond the notion of a we-mode and embrace what I introduced above as "role-mode". What, among other things, distinguishes this level from that of informal pure we-mode groups is that people and groups act, think and speak in more or less strictly defined roles, say, as finance minister of the government, as committee members, or as employees of a corporation. The canonical expressions of positions taken in the role-mode are therefore phrases like "As president of the United States, I declare...", “As members of the committee, we intend...”, and so on. I think that this proposed extension of his apparatus through the notion of role-mode may be one Tuomela is particularly open to. I take it he has something like this in mind when, for example, he says that "we might also speak of a positional or institutional mode that psychologically can involve either we-mode or I-mode thinking and action" (37). Again, this is a problem that can be solved by recognizing a new kind of mode beyond the we-mode.

Finally, let me address the ontological picture of SOCIAGA and mode approaches more broadly. Above I described it as an essential part of the mode-approach to collective intentionality and indeed as one of its at least prima facie most attractive features that it combines a commitment to the conceptual irreducibility of the 'we' with a rejection of ontologically mysterious collective entities like the group conceived of as just like another person, or as a group mind somehow free-floating with regard to the group members, emergent in a very strong sense. As long as we strictly stick to the kind of description I have just used, I think this is also a position that we can and must uphold. However, I also employed a more sweeping characterizations in the form of the slogan "conceptual reduction: no, ontological reduction: yes". This slogan suggests that we could accept the conceptual irreducibility of the "we" and collective intentionality generally, without incurring any kind of ontological commitment beyond that to individuals and their minds. Though I cannot make the full argument here, it seems to me that this position, while tempting, is very problematic on reflection. Let me just put the basic point in the form of the following question: if the world contained no irreducible collective entities, why couldn't we just do away with the collectivistic language? Why would the "we" be irreducible if there is no collective subject for it to refer to? One answer 
to this question is that while we could eliminate collectivistic language in principle, it is a useful shortcut for getting at features of the world that ultimately do not involve anything irreducibly collectivistic. A good response to this in turn is that it is not at all clear what it means to get at features that are not collectivistic through the use of language that is. An even better response of course is to give an account of collective entities that shows that there is really nothing deeply objectionable about them.

But couldn't such an account be fictionalist and constructionist like SOCIAGA's account of group agents? I think there is something right about this talk of constructing and creating groups. But it takes care to say exactly what. Are group agents really fictions in the sense in which novels, plays or TV dramas are fictions? That is certainly not what Tuomela wants to say. Obviously real corporations like IBM are not fictitious in the sense in which Ewing Oil is fictitious. But then in which sense are they and their attitudes fictitious? I will argue that there is no clear sense in which they are. They are part of the real world, not any fictional world. And if it is true that group agents should be understood at least partly in terms of role-mode states of individuals, it can't be quite correct either to say that their intentionality is merely derived. The intentionality of somebody who plans the company strategy as a CEO, or who has certain obligations as a police officer, is certainly intrinsic. So I will also explore whether the subject mode account can guide us towards an alternative way of showing that groups and group agents are non-mysterious, that they are neither mere sums of individuals, nor free-floating or like additional people. I will defend a simple common sense answer to what they are: they are individuals as related in certain ways. And I will propose that these relations are at least in part intentional relations. That is, representation is at least partly constitutive of groups and subject mode representation plays the fundamental role here. Just like an individual "I" is partly what it is through its capacity to represent itself as "I", a "we"-group is partly what it is through its capacity to represent itself - through its members - as a subject of joint attitudes, and an organization is partly what it is through the capacity of its members to represent themselves as taking certain positions in their organizational roles.

Let us take stock of the argument so far. I've indicated four problem areas for Tuomela's version of a mode approach to collective intentionality. First, I've asked how the we-mode is manifest in the minds of individuals if it is not part of intentional or phenomenal content in any sense at all, arguing that Tuomela does not give an unambiguous answer to this and that his most 
likely answer collapses into the content approach. Second, I argued that reasons usually are and should be understood in such a way that whether something is a reason for something is sensitive to content, so that if there are group-specific reasons, such as those Tuomela appeals to in his account of the we-mode, we should expect there to be group-specific content, too. Third, I argued that there are also problems for Tuomela's project of giving an account of all forms of collective intentionality in terms of such notions as group reasons and commitments, suggesting that joint bodily action, joint attention, and joint habits and patterns are elementary forms of collective intentionality that do not involve reasons and commitments. Fourth and most fundamentally, I pointed out certain limits of the strategy of a mode-account of collective intentionality to combine a robust realism about we-intentionality with avoiding any commitment to mysterious group entities. This cannot and should not mean that all commitment to group entities is avoided, but only really that such group entities must be non-mysterious. I began sketching what I hope is such a non-mysterious account: groups are individuals as intentionally related in certain ways. In the remainder of this paper, I want to develop this sketch further - though it will still have to remain a mere sketch - and show how it can solve the problems I have indicated.

\section{Mode as representational}

I believe the main reason why we have not yet come up with a satisfying account of mode and specifically of the we-mode and thus of collective intentionality is the strong grip that the received view of a propositional attitude (compare McGrath 2007) still has on our philosophical imagination. The following features of this view, which tends to be taken for granted by contemporary philosophers, are particularly important for present purposes:

1) The content of a propositional attitude is identical to that of the relevant proposition. The subject and the mode of the attitude make no contribution to content.

2) The proposition is a truth-value bearer (indeed the constant, underived truth value bearer) and yet at the same time it is part of practical attitudes like intention as well as theoretical attitudes such as belief.

3) The proposition is the object of the attitude. 
Note that given the acceptance of this picture, it is hard to see how there can be a satisfactory answer to the question that I posed earlier, namely what contribution the we-mode as conceived in SOCIAGA really makes to intentionality. The traditional view is inspired by reports of propositional attitudes, where the subject and its attitude just appear as the object of another subject, and so neglects how the subject and its position figure in the subject's own mind.

I have criticized the traditional view extensively elsewhere (Schmitz 2013a; Schmitz forthcoming) and don't have the space to repeat all these arguments here, so I will be brief. To begin with the last point, propositions are not the objects of intentional states except in special circumstances such as, for example, when Californian voters make up their minds with regard to the propositions on their ballot. Rather the object of, for example, the belief that it is raining is the corresponding state of affairs. Now suppose that the same state of affairs is also the object of an intention to make it rain. (The subject of the latter attitude, let us suppose, since the military has the capacity to make it rain, is a general. The subject of the former attitude observes this later - it may even be the same general.) On the traditional view, even this practical attitude in some sense contains something that, because truth is representational success from a theoretical, mindto-word direction of fit position, can only belong to the theoretical domain. However, on reflection it is hard to make sense of this idea. It is not that the general predicts that it will rain on the basis of evidence in favor of this prediction. It is rather because his meteorologists tell him that it will not rain that he decides to make it rain! Nor is it plausible, some philosophers to the contrary, that intending is itself a form of believing. So I don't think that there is any sense in which the intending general takes a theoretical position vis-à-vis this state of affairs or that his practical attitude contains something theoretical. Rather the part of his attitude that represents the state of affairs (in this case, the action) that the belief is also about, is not yet a complete posture - that is, a bearer of a truth or other satisfaction value, a speech act or an intentional state. To get such a posture, we need to add the theoretical or practical position of the subject vis-à-vis the state of affairs. (The mistake of 2) of the received view is to assume that the element common to different kinds of postures could be represented by something that itself has a satisfaction value.)

Now again, the crucial claim I want to defend is that this position is itself represented. The subject represents and is aware not only of a state of affairs, but of his or her - or our position vis-à-vis that state of affairs, or, as we can also say, her relation to that state of affairs. This awareness is typically backgrounded, the focus typically on the state of affairs, but it is still 
there. In order to be said to be intending, the general must have some awareness that he takes it upon him to bring about that it rains, that he takes practical responsibility for this.

Correspondingly, in order to be said to believe something, a subject needs to be aware that the belief should have some kind of basis, and that she takes theoretical, epistemic responsibility for the reality of the relevant state of affairs. Note, however, that the claim is not that the subject needs to apply a concept in taking up the posture, or need even to have such a concept. It is surely implausible that one should need the concept of belief to believe or the concept of intention to intend. Rather, it is sufficient that the subject have a sense of her position, as one can e.g. have a sense - perhaps a background sense - of somebody as a potential cooperation partner without having the concept of a cooperation partner. Similar remarks apply to speech acts. In assertion the subject presents herself as believing or perhaps even knowing that a certain state of affairs obtains, in ordering as wanting that a certain action be performed. So the thesis is that both mode in the sense of attitude mode and its linguistic counterpart, what is traditionally referred to in speech act theory as force or illocutionary role, are representational.

Before I come to explain the relevance of this to the theory of collective intentionality, let me note a couple of further advantages of the proposed fundamental revision of our understanding of propositional attitudes. The first departs from Searle's - to my mind convincing - argument that, for a variety of postures such as actional and perceptual states, memories, intentions and orders, there is a causal component to the satisfaction conditions of these postures and, at least for certain basic postures, a characteristic difference between theoretical and practical ones that corresponds to the difference between them in terms of direction of fit. For example, an intention or order needs to cause what is intended or ordered in order to count as executed and thus as satisfied, while a perceptual state or a memory needs to be caused by what is perceived or remembered in order to count as veridical or true and thus as satisfied. Under the influence of the traditional framework, Searle sought to capture this by inserting into the propositional content of these postures a clause to the effect that they themselves cause the relevant state of affairs or be caused by - he refers to this as "causal self-referentiality" (Searle 1983). But apart from the fact that the postulated self-reference of a posture in its content seems potentially problematic and that, given that Searle assumes that the content of all these postures is propositional and conceptual, he seems committed to the implausible view that, for example, merely to have a perceptual experience, a subject needs to have a concept of experience, there is 
a further implausible consequence of his analysis that I want to focus on here. It is that under Searle's analysis it would not be possible for an intention and a belief, nor indeed for any pair of postures which differ with regard to direction of fit, and where at least one is causally selfreferential, to have the same content and be directed at the same state of affairs. This is because for all causally self-referential practical, world-to-mind direction of fit postures, an active causal relation, with the posture causing the state of affairs, would have to be included in the content, and for all causally self-referential theoretical, mind-to-world direction of fit postures, the opposite, passive one. This would mean that the postures would either have different causal relations and self-references in their content, or, in the case of those that are not causally selfreferential, as Searle assumes for belief, they would lack such causal self-reference altogether. But, as our example above illustrates, it is implausible that there should never be beliefs and intentions directed at the same state of affairs.

To put the point in an even simpler way, the difference in mind-world causal relations between intention and belief just does not seem be a matter of what is believed or intended, but comes down to the difference between believing and intending itself and thus to what I propose to call attitude or position mode. To locate this difference in what from now on I shall call "what-content" or "state of affairs-content" is an artifact of the traditional view and its conception of content. What the subject, for example, intends when she, say, intends to close the door, is not the state of affairs of herself causing this action. It is rather that she represents this action from a position of directedness at causing it. So the alternative to Searle's account I want to propose is to say that the subject of - to stick with our example - an intention represents her position and has at least a sense of that position as an active one that is only satisfied if it causes the intended action.

Searle arrives at his account on the basis of three key observations or principles: first, that (at least) some satisfaction conditions have the causal components we discussed; second, that satisfaction conditions (as thing required; see Searle 1983, chap. 3) must be determined by intentional content; third, that intentional content is propositional (and conceptual) content in the sense of the traditional model. I accept the first observation and also the second principle, notably against externalist, disjunctivist and so-called relational, as well as radically enactivist theories, which all, though partly for different reasons, try to work with a notion of intentionality without representational content. In what follows, I will only be able to discuss this briefly in a 
couple of places, so at this point let me just state my general conviction that conditions of satisfaction can only be determined by the mind - I have no idea what else could - and the stipulation that "intentional content" refers to that feature of intentional states that determines their satisfaction conditions. ${ }^{7}$ Given my criticism of Searle's account and thus of the third point, I think the first two points provide a powerful argument in favor of the idea that mode is representational.

To return to the main line of argument, the second general argument in favor of this thesis, which I can only discuss even more briefly here, though it is even more important, is that once we clearly separate the notion of what-content as that what represents a state of affairs and may be shared between different theoretical or practical postures, from the theoretical or practical positions vis-à-vis those states of affairs, we also open up the possibility of generalizing standard propositional and quantificational logic, so that we cannot only formalize deductive inferences with propositions, but with arbitrary postures. For properly understood, propositions at least as they occur in standard propositional logic, are just statements, that is, what-contents with a statement-mode, while, again, propositions as what is supposed to be common between different attitudes, are best thought of as incomplete what-contents. (The traditional view of propositions and propositional attitudes fails to realize that it ascribes two different and incompatible roles to propositions in the context of propositional logic and when talking about propositional attitudes.) So basically all we need to do is to add mode symbols to the apparatus of standard logic as an additional category of non-logical signs which complete the postures. The postures are then our Elementarsätze, on which we can now perform all the same logical operations which we used to perform on statements alone. This "mode logic" (Schmitz manuscript) is a generalization of standard propositional logic because we can think of that logic as a special case of mode logic, namely the case where only the statement mode is allowed. Accordingly, mode logic preserves satisfaction rather than truth, because truth is a special case of satisfaction. With mode logic we can now also, for example, allow imperative force / mode and

\footnotetext{
${ }^{7}$ On this understanding, it is true by definition that satisfaction conditions are determined by intentional / representational content, and I think it could be shown that those who attempt to do without content do so because they associate more with this notion than is contained in my stipulation. For example, they implicitly or explicitly assume a language-centric notion of content and representation and suppose they must be symbolic, or they assume that content is an
} 
account for pure imperative deductive inferences, but also for mixed inferences which involve both imperatives and statements. We can also allow promises, wishes, and so, and even all kinds of intentional states. It seems to me that it is not much more than an accident of history that in the common understanding, logical inferences are often thought to be restricted to linguistic entities.

I have spent some time laying out the case for attitude mode / force being representational at least in rough outline because it gives us a good starting point for the argument for my proposed reconceptualization of the we-mode (and other modes of collective intentionality). The next step to what I will call "subject mode" is comparatively easy. For a subject cannot represent its relation to some state of affairs without representing itself. For example, I cannot represent my passive position vis-à-vis the objects of my perceptual states without representing myself. I experience these objects as impressing themselves on me. Put generally, the claim is that every posture also has an aspect of self-consciousness. We are never aware of objects (including states of affairs) from nowhere, as it were - and as by nobody - but always situate them in relation to ourselves - spatially, temporally, causally, cognitively, conatively, and so on - and even in relation to our social and institutional position, as we will soon discuss. Self- and object-consciousness are inextricably linked, as Immanuel Kant argued already and many others such as Ludwig Wittgenstein, Peter Strawson, Jean Piaget and Gareth Evans have since, often under Kant's influence. And the most characteristic and fundamental use of 'I' is its use in subject position (Wittgenstein 1958), which may even be immune to error through self-identification (Evans 1982). That is, I can be wrong about whether it is my arm that I'm seeing, but not about the fact that it is me who is seeing the arm. In the terms I have introduced, the key to understanding self-awareness is to understand how it occurs in subject mode position, not as part of the what-content, of what I see, think, or am otherwise aware of.

The subject mode approach to collective intentionality ${ }^{8}$ attempts to extend this thought from I-intentionality to we-intentionality - and then to role-intentionality. It propagates the thought that we should understand collective intentionality not in terms of what is believed about

object of the mind, so that, for example, perceptual content would intervene between mind and world and block direct access, so to speak.

${ }^{8}$ A related, but different account in terms of plural self-awareness is provided by Hans Bernhard Schmid (2014a). For a discussion of some of the differences see his contribution to this symposium. 
us, or what is intended with regard to our actions, but in terms of believing and intending things jointly with others. The next step now is to see how this kind of approach plays out at the level of joint intentionality below the level of practical and theoretical thoughts, of beliefs and intentions. Just as there are pre-linguistic, non-conceptual and non-propositional forms of individual selfawareness (Bermúdez 1998), for example in perception and action, there are also corresponding forms of collective self-awareness in joint attention, perception and action. These are below the level of rationality and reasoning and do not involve reasons and obligations. It is to these forms of collective intentionality that I now turn. Getting a sense of how the mode-approach can be extended to account for them will help us with one of the problem areas for Tuomela's we-mode approach outlined above and will provide us with a model for understanding the other levels.

\section{The mode of joint attention: the RAIMO account}

The point that the jointness of a posture is not a matter of what we jointly intend, believe, or know, can be put even more nicely at the level of joint attention: the jointness of jointly attending to something is not a matter of what we attend to, but who we attend with (compare Campbell 2002, chap. 8). It's not that we are mutually focused on one another, but jointly on a third thing. The idea of the mode account of joint attention is that the with-part can be explained in terms of subject mode representational content. The jointness is manifest in how we experience the other in our shared triangular relatedness to the object of attention. The main task of this section is to explain what it means to experience the other as a co-attender, or, as I shall also say, a 'cosubject' of attention rather than as its object. ${ }^{9}$ To accomplish this, it will be useful to first briefly discuss some alternative accounts.

Some accounts treat joint attention as a merely perceptual, purely cognitive phenomenon. But I don't know how joint attention could be distinguished from mere mutual attention in purely perceptual terms. To see this, consider the following scenario (with apologies for its homicidal character): two people are focused on the same target, a high-ranking politician. One wants to shoot him, the other, the politician's bodyguard, wants to protect him. The bodyguard tracks the assassin out of the corner of his eyes because he has become suspicious of her. The assassin also tracks the bodyguard's attention because if the bodyguard loses track of her, he will have the time to get his gun out and shoot the politician; otherwise the bodyguard could shoot her first. So 
these two are attending to the same object, they are mutually aware what the other is attending to and there is a causal relation between the direction(s) of their attention(s) - as has been suggested by some as a condition in an analysis of joint attention (compare Campbell 2002, 162f). Still, it seems clear that this is not an instance of two people attending to something jointly. Mutuality is not the same as jointness. How do we get from there to jointness. I think we need to add a prosocial motivation and at least a disposition for joint action.

This is in accordance with how joint attention is understood in developmental psychology, where a prosocial motivation to share an object, even to share it for the sake of sharing, is taken to be criterial for joint attention (Carpenter and Liebal 2011), which is often thought to be unique to humans - primates generally don't walk around pointing out exciting things to one another. Joint attention episodes are usually taken to begin at around 12 months of age, and are thought to often display a tripartite structure of (1) initiation by getting the other's attention, followed by (2) a referential point to the object to be shared, before culminating in (3) a 'sharing look', the comment on the object, which closes the triangle through an affectively charged meeting of minds. The affect can be sheer pleasure and excitement about the object; concern, for example in 'social referencing' when an infant checks back with someone, often the caretaker, whether a situation is safe; puzzlement, eye-rolling, and many more. I interpret the sharing here as a joint communicative action. It may be initiated by one individual, but it's only successfully completed if the invitation is accepted and the co-attender directs her attention to the object, so that joint rapport with it is established.

Note that the claim is not that sharing is the same as joint attention, but just that one can only be in joint attention mode when one is also disposed to a joint communicative or other joint action. To highlight this irreducibly practical aspect of joint attention, some prefer the term 'joint engagement' (R. P. Hobson and Hobson 2011). However, while in philosophy and some fields of psychology attention is often treated as a purely perceptual phenomenon, the common sense understanding of "attend" clearly also has the pragmatic meaning, for example, when we say that the nurse attended to the patient. I will therefore stick to the established terminology. A consequence of our observations is that jointly attending as such is neither a mind-to-world nor a world-to-mind direction of fit state, but comprises episodes of both kinds. ${ }^{10}$ It is a joint

\footnotetext{
${ }^{9}$ In this section and the next I draw on some material from (Schmitz forthcoming).

${ }^{10}$ Thanks to Olle Blomberg for pushing me to get clearer about this.
} 
experiencing of an object that in many cases has already been established through a joint communicative action and in any case brings with it a disposition for communicative and other joint actions. Finally, to conclude the discussion of definitional matters, there are also more intellectual forms of joint attention, such as we-mode deliberation and discussion, say in a board meeting or in a seminar, but, in accordance with most writers on the topic, I will here restrict the notion to the more elementary, sensory-motor-emotional forms of attending jointly.

In what follows I will mostly ignore the debate about the disjunctivist, so-called 'Relational View' of joint attention (Campbell 2002; Seemann 2011), since it is largely driven by epistemological motivations which are orthogonal to the concerns of this paper. I have also made some general comments on the notion of intentional content, so let me just state briefly why I think it also ought to be applied here. Of course it is true that joint attention is relational in the sense that the co-attenders participate in a triangular relation with each other and the object that they jointly attend to. But the existence of this relation still depends on the intentional contents in the minds (and heads) of the participants in this relation. If my attention had slipped away, we would not have attended jointly. And this also means that there can be and sometimes are illusory experiences of jointness, as when you turn to me excitedly to share something only to discover that my attention has wandered away from the movie you were experiencing as an object of joint watching. So we need a notion of experience and an understanding of intentionality that allows us to locate experiences and intentional contents in the minds of individuals, in the good cases where we do attend jointly, as well as in the bad cases of illusory experiences of jointness. And only intentionalism can provide such a notion and such an understanding. Even more pressing with regard to our present concerns, we need the notion of intentional content to explain the specific way in which we experience somebody as a coattender and a co-subject rather than as a mere object of our consciousness. It is hard to see how this could be accomplished merely in terms of saying that this person is a constituent of a joint attention relation. This is just what needs to be explained.

In accordance with the thesis of an inextricable relation between self- and objectawareness, I will then argue that the way I experience the other is also reflected in how I experience the world, or rather in how we jointly experience it. There are two main sources of inspiration for the idea that we experience others as co-subjects. One I have mentioned already, Wittgenstein's distinction between subjective and objective uses of "I". The other is the linguist 
Ronald Langacker's idea that we construe an entity subjectively when we construe it as part of or in relation to what he calls the ground, by which he means the speech situation with speaker and hearer, the immediate context, mental background, and so on (Langacker 1987). I will extend the notion of such subjective construction from linguistic, semantic content to the intentional content of experience, and accordingly I will speak of experiencing others as co-subjects or subjectively.

The basic idea here is that to experience something subjectively is to experience it as an extension of my (and thus as part of our!) perceptual or actional apparatus. Langacker uses the example of how you experience the glasses that you are wearing: normally your attention is not focused on them and you are mostly just aware of them (if at all) as something that improves your access to the world. Or think about how a tennis player experiences his racket as an extension of his actional apparatus, as improving his actional reach in the world. These examples can serve as metaphorical models for how in experiences of jointness we experience the other as a potential or actual partner for theoretical, epistemic as well as practical cooperation; as a source of information about the world and at the same time as somebody who will help and guide us; as somebody who draws my (our!) attention to new, exciting, interesting things and who I in turn want to show interesting things to; but also as somebody who I can trust in a dangerous situation (e.g. social referencing). This is how to experience somebody as a co-subject of perception and action and thus a part of a shared, common ground rather than as a mere object of one's intentionality.

Again, this part of our experience is typically backgrounded; we are focused on the objects of our attention, not the co-subjects. When we focus on the other, we invariably construe her more objectively. We then look at her, not with her. (This is certainly at least partly what people have in mind when they talk about 'objectification'.) The level of experience we are talking about here is also the level where we are attuned to others, resonate with them and are aligned with them in various ways, for example, with regard to mimic, gesture and posture. That we are more sympathetic to those who are attuned to us more or even imitate us with regard to such features and are more likely to respond positively to their wishes and requests is a wellknown phenomenon often called the 'chameleon effect' (Chartrand and Bargh 1999).

The interdependence of self- and object-awareness means that the jointness of joint attention is not only manifest in how the co-attenders experience each other, but also how they see the world 'with each other's eyes'. So those who are bound together in a joint attention 
episode often experience the world as containing things that they want to draw the other's attention to, but also that they might want to shelter him from; as good and interesting or bad and boring for the other, and as like or unlike things they have jointly experienced in the past. That is, joint attention means that the co-subjects are attuned and aligned with regard to cognitive and conative interests as well as with regard to their physical features and stances and that we often experience the world in relation to us and our common ground of shared interests and past experiences. A recent result from developmental psychology nicely illustrates and supports this point. Infants shared several toy ducks with one experimenter and then several teddy bears with another. They then entered a room with just one of the experimenters, in which a duck and a teddy bear picture were on the wall, and were much more likely to point to the picture of the object they had earlier shared with the experimenter they were with (Liebal et al. 2009).

There is some evidence that subject mode intentional content rather than state of affairs content explains certain kinds of social understanding and social actions based on that understanding. For example, 14-months-old infants understood an ambiguous request by an adult on the basis of a shared joint attention episode, but not by merely observing his otherwise identical interactions with the relevant objects. After the adult and the infant had shared two objects and the infant had explored one object alone, the infant was able to correctly interpret an ambiguous request for "that one", made with an excited expression by the adult, as referring to the new object. But 14-months-old infants were not able to do the same in conditions where infants merely observed e.g. the adult examine the objects by himself, or the adult engaging in joint attention with another person (Moll, Carpenter, and Tomasello 2007). Moll and Meltzoff conclude that "joint engagement is thus at least helpful, if not necessary, for infants of fourteen months to register others as becoming familiar with something" $(2011,397)$.

From the present perspective, what is most important about these experiments is that they show that the infants could understand the relation of familiarity between the adult and the old object and thus that the other object was new and interesting relative to it, as long as it was part of a shared familiarity, a common ground established by joint attention, but that they could not understand it merely on the basis of observation. I think this strongly suggests that the affectively charged subject content rather than the object content explains the infants' understanding of the adult's request. They understood the adults relation to the familiar object as part of the attention 
relation they jointly experienced with her. This explains why they were able to cooperate with the adult by means of handing over the desired toy.

Further insights into how others are experienced, understood and treated in joint attention come from studies that reveal the characteristic deficits autistic children show in this regard. Strikingly, when asked where a sticker should go, more than half of the children with autism, but not a single non-autistic child, never indicated the place by pointing to their own bodies rather than at the other's body (R. P. Hobson and Meyer 2005). I find this a very vivid illustration between a co-subjective and an objectifying style of reference. To point to a place on one's own body to pick out the corresponding place on that of the other, is to treat her as somebody like oneself rather than as an object. Research also shows a correlation between sharing looks and role reversals in joint action, so that Peter and Jessica Hobson conclude that "the mode of social perception that involves sharing looks [also] gives rise to self-other transpositions in imitation" $(2011,124)$. Autistic children further engage much less in the kind of affirmative nodding people often display when listening to others, and only 3 of 16 children with autism showed a concerned look when the drawing of the tester was torn in a joint attention situation (J. Hobson et al. 2009), revealing that autism is also connected to deficits in experiencing the world with the other's eyes, with regard to their interests and concerns.

What's the common denominator of these findings? A slogan that I find useful here is that joint attention subject mode experience is a form of 'like-me'-intentionality. I experience somebody as like me, when I feel that I can take on any role she can, facilitating role reversal; when I identify with her, am aligned with her and tend to affirm her postures; and when I refer to her through sameness, that is, through imitative forms of representation. There is also a handy mnemonic device to remember these properties. Given the role Raimo Tuomela has played for so many years in the community of collective intentionality researchers - as one of its pioneers; as an essential part of its epistemic apparatus, who has opened our eyes to many things; as an important force on the practical, organizational side of things, who has helped many of us; and last, but not least, as a very nice human being - it seems more than appropriate to call the account of joint attention that I have just sketched the RAIMO-account. It accounts for joint attention in terms of the RAIMO-properties, that is, in terms of representational states that further role reversal and reciprocity; that are affectively charged and connected to the attunement, alignment and mutual affirmation of their subjects; that involve imitation of and 
identification with these co-subjects; that represent in a subject-mode, and in a non-conceptual representational format.

What does it mean that joint attention experience has a non-conceptual representational format or structure? I believe that the structure of representations - of intentional states, spoken as well as written language and other forms of documentation and pictorial depiction - can be distinguished in terms of such properties as their gestaltlike character; the degree of differentiation of representational role; of their context dependence; of their abstractness / concreteness; of their externalization and standardization. So joint attention experience lacks the kind of elaborate propositional, logical and grammatical structure of representational roles - say of grammatical subject, verb, adverb, object etc. - that we find at the level of speech. It is also, in contrast to joint beliefs and intentions, dependent on the context of immediate interaction and more concrete than such conceptual level representations. The levels to which representations with different formats belong also show a certain degree of autonomy. This means that there can be conflicting representations at different levels. So just like the content of perceptual experience is independent of our beliefs and can conflict with them (Evans 1982), there may be a strong bond between people on the sensory-motor-emotional level, while on the level of reasoned values and plans they find they should rather stay away from each other - or this situation may be reversed.

Different levels of collective intentionality can further be distinguished in terms of such properties as the degree of role differentiation between group members and the size of the relevant groups. So while joint attention of the sort we have discussed - as opposed to, say, the whole world watching the moon landing or a world cup final - connects small groups of people typically even dyads - which have more or less equal roles, elaborate institutions and organizations require a high degree of role differentiation and correspondingly large groups. You wouldn't find, say a hotel receptionist, in a small tribe.

I'm not sure whether the distinction between levels is just a matter of degree, or should be understood in a more categorical way. For purposes of a rough orientation I find it in any case convenient to distinguish three levels: the non-conceptual, the conceptual, and the documental one. These levels correspond to pre-linguistic intentionality, and spoken and written language, respectively. To illustrate, consider some kids kicking around a ball and establishing patterns of acceptable play through sensory-motor-emotional interactions; conceptualizing and negotiating 
rules for the game and passing them on in oral traditions; establishing organizations with functionaries in a variety of roles that write down and standardize the rules coming from different oral traditions. ${ }^{11}$

As this example illustrates, the affective, actional and perceptual experiences that we have been talking about so far also ground corresponding dispositions. People are tied together by joint tendencies, patterns, habits and skills. These provide the kinds of bonds between people that, as I argued earlier in the context of the example of walking together, are prior to the conceptual level of deontological relations like obligations and commitments, attitudes like belief and intention, and reasons and reasoning. So we have at least a sketch of an account of nonconceptual collective intentionality, which can overcome some limitations of a pure we-mode account like that of SOCIAGA. Moreover, I hope to have shown how the notions of subject mode and position mode content are useful for describing and explaining what is going on at the non-conceptual level. We will now see how the conceptual we-mode level is created on top of it, how this allows us to better understand and demystify the irreducibility of the "we", and how the thesis of mode representation helps us to solve or rather dissolve the puzzles of common knowledge and group-relative reasons and reasoning.

\section{From joint attention to we-mode and role-mode}

Let us return to the earlier example of a couple that through the sensory-motor-emotional exercise of walking together has established a bond and a joint habit of going on the same walk together. (It is certainly no accident that there is a well-worn cultural practice of testing attraction and erotic compatibility through joint sensory-motor actions such as walking and dancing together.) In principle their interactions could remain on the non-conceptual level for an indefinite amount of time. But at some point - and in real life normally sooner rather than laterthey will start planning their walks. As we imagined above, one of them might say: "I can't come tomorrow, but let's us walk again together the day after tomorrow!" This illustrates a fundamental function of the conceptual level relative to the non-conceptual one and generally of higher levels of collective intentionality relative to lower ones, namely to manage disruptions and crises and create more enduring social bonds through less context-dependent forms of

\footnotetext{
${ }^{11}$ For more discussion of levels of collective intentionality and their relation to representational format, see (Schmitz 2013b).
} 
representation. If language hadn't been available, the sensory-motor bond and habit might have been broken right there. But through language this can be prevented. (Should they get married, similar functions could be performed through the broader institutional context and the larger group into which it is embedded.)

Against the background of their non-conceptual bond, the couple can say "we" in that affectively charged way that is a sure sign that a truly collective, not merely distributive, interpretation of the first person plural is in play. And through language they can take their relationship to the next level by negotiating common values and a shared narrative, and by establishing joint plans, commitments and obligations. On the basis of being co-subjects of joint attention and action and joint dispositions, they begin to create a joint subject of conceptual level postures through their interactions, their joint reasonings, deliberations and negotiations, and grow more and more into actually being such a subject. I see nothing objectionable or even mysterious in the idea of such a subject. It's not a mere summation of individuals because "we", at least in its collective reading, picks out these individuals as being related in certain ways, first through non-conceptual, sensory-motor-emotional bonds, then increasingly through being the subject of conceptual level attitudes. Nor is this relatedness like another person, or emergent in some mysterious or objectionable way.

The we-mode as representational approach also dissolves traditional puzzles about how attitudes such as joint attention and common knowledge can be represented. The literature here has been dominated by approaches in terms of some potentially infinite iteration of states (e.g. Schiffer 1972), as in the following example:

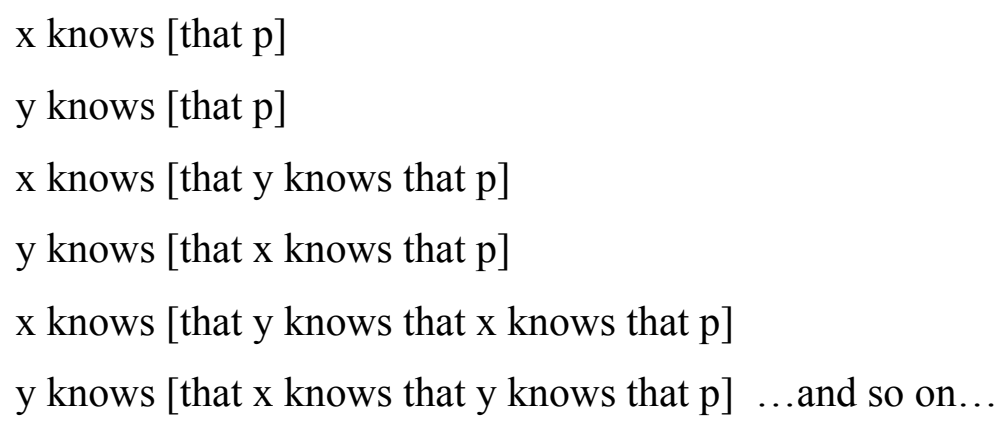

This infinity results if we try to eliminate the "we" and to treat mode as mere object of ascription from an external point of view and as non-representational. Then each iteration of ascribing 
knowledge to the other will produce a new position with regard to that knowledge which is itself not represented - here symbolized by the fact that it appears outside of the square brackets. When that position is then represented, yet another new position is created, and so on, ad infinitum. But if we allow ourselves to use the first person plural and accept that subject and position mode are representational, we, respectively any member of the relevant group, or the group in unison, can just simply say, or think, for example, "We know that it rains" to indicate common knowledge of the fact that it rains.

Note that on the present proposal, our statement is not an expression of an (individual or collective?) state of belief or knowledge that we know that it rains. This would mean that the linguistic representation would once more be an expression of a mental state where the subject takes a further position with regard to the linguistically represented situation, which position would again not be represented, reintroducing the traditional picture. That is, we would get something like "I know that we know that it rains", and then the question would arise whether the other person knows this and knows that I know that we know, and so on. Again, what is represented through mode representation is not again represented from another theoretical or practical point of view 'behind it'. The infinite iteration is stopped at the first step. It is just that both of us, so to speak, we-know that it rains. This is of course not to deny that we can say or think something like "We know that we know that it rains" or even iterate this further - though we shouldn't be too sure either that we have a clear grasp of the significance of these iterations. The point is just that the potential infinity of iteration should not be thought of as what represents the commonality of knowledge or other postures. Note once more that this dissolution of the puzzle is only made possible by accepting the representationality of mode. Only because subject mode represents the 'we' as the subject of the position and not as its object, can we make sense of our common epistemic position.

But isn't the subject of any particular posture as I have described it an individual? So, who is really the subject of the state of common knowledge (belief, intention, attention etc.), is it the individual or is it the collective? The answer is that the individuals are jointly the subject. That is why it is a plural subject. The key here is to see that we can and must ascribe the state to both the individuals and the group because the individuals jointly make up the group. An individual thinks our thought from the we-perspective of a group member and so represents the group state. Fittingly, the labor of representing the group's postures in the partially group- 
constituting subject mode is essentially shared between its members. The group represents its postures by one or more of its members representing it. We will below return to the question how collective subjects can be constituted, created, constructed, or otherwise brought about through representation.

The subject mode account is also superior to one that accounts for any kind of collective posture as a special kind of posture - as opposed to a posture with a special kind of subject - as Searle (1990) does in interpreting we-intentions as a special kind of intentions that still have individuals as subjects in his version of the we-mode approach. In contrast, on the present approach we can give an interpretation of we-intentions and any kind of we-subject postures that is both compositional and referential. We are not dealing with a special kind of intention, but with an intention had by a special kind of subject, a "we" that can also be the subject of various other postures. It is essential under the present proposal that sentences like "We intend to do X" or "We will do X together as a group" have readings where they are interpreted as expressions with a world-to-mind direction of fit, rather than as mind-to-world statements about intentions and therefore noteworthy that SOCIAGA also emphasizes the possibility of such readings (77). Tuomela also rightly underlines that we-mode intentions have different satisfaction conditions than I-mode intentions (70). I think this even true when we consider aim intentions where the object of the intention is a state rather than an action. For example, if I intend for it to be a good meeting, this has different satisfaction conditions than if we intend this, because in the latter case we rather than just I are poised to intervene to bring about a good meeting. Note that if we accept this together with the principle discussed above that satisfaction conditions must be determined by content, it follows that the difference between my and our intention must be reflected in content.

Given the representationality of mode, we can also give a straightforward account of group reasons, which above I had described as a potential problem for Tuomela's account. Let us suppose here with Tuomela that reasons are facts or state of affairs. However, as he rightly emphasizes, states of affairs can only be reasons for a subject insofar as the subject recognizes them as such $(2013 \mathrm{a}, 99)$. To continue with the example used earlier, that it is raining can only be our reason not to go hiking if we are aware of this state of affairs and aware of it as disfavoring hiking. The point is now simply that the mode as representational approach can very easily account for group reasons because of its core claim that the subject's position vis-à-vis the 
state of affairs is always represented. So, for example, if my position is just my personal, I-mode one, I will be aware of the fact that it is raining from the vantage point of just my personal preferences and, since I have a nice new rain jacket and enjoy hiking in the rain, it won't be a reason for me not to go hiking. But from the collective we-mode point of view of the group, the fact that it is raining is a reason not to go hiking, because most of the other members of the group don't like hiking in the rain and some don't even have a rain jacket. So whether a state of affairs is a reason for something for a subject, depends on the relevant, individual or collective subject. This is also emphasized in SOCIAGA:

When I have a we-mode intention to participate in our seeing to it that $\mathrm{P}$ in the we-mode, my group reason is not the mere content $\mathrm{P}$ of our acceptance, but the reason also involves the fact of our acceptance of it as our intended goal. (69)

And it is most straightforwardly accounted for on a view which says that that subject (and its position) are themselves represented. How otherwise would it enter the picture?

An equally straightforward account can be given of collective reasoning. I'll focus my discussion on deductive reasoning here. Suppose our group has agreed to go hiking if it does not rain, committing to a collective intention conditional on a certain state of affairs. The antecedent of this conditional is also naturally construed as being in the scope of a 'we' - though this is not usually explicitly represented because we tend to take for granted that we can agree on facts, at least on facts of this kind. If we do agree that it rains, we are logically committed to detach the antecedent and to collectively intend to go for a hike. Again what is represented are not beliefs or statement about our beliefs and intentions, but those postures themselves, so that the conclusion of the argument is really an intention, as it should be. And it is easiest to integrate subject and position mode into our received ways of thinking about logic and deductive reasoning if we think of them simply as representing the subject and its position. Similar remarks apply to the central argument of SOCIAGA with regard to traditional game-theoretic puzzles such as Hi-Lo and PD. As Tuomela shows, we can dissolve these puzzles when the relevant choices are seen from the we-perspective. This naturally combines with a view according to the which the vantage point of its individual or collective subject is represented in any posture. 
Corresponding arguments can further be made with regard to role mode. There are attitudes that individual and groups hold as the bearers of certain institutional roles, but not as the bearer of other such roles, or as private people or informal groups. For example, Angela Merkel may have criticized the SPD as leader of the CDU, but not in her role as chancellor of Germany. With politicians, it is often especially important in which of their usually many roles they have taken certain positions. But similar issues can be relevant in virtually all domains of contemporary life. Was the policeman on duty, did he act in his role, or not? Did he obtain the evidence in an admissible way, so that he can base official measures against the suspect on it? Questions like this can be of great legal and other significance.

The canonical representations of role mode are the "As [role]"- locution or the "In my role as [role]"-locution, as in the following:

As chancellor of Germany, I believe that...

As members of the committee, we intend to...

In my role as policeman, I arrested...

The crucial point for present purposes is that because attitudes are in some cases role-specific, so are reasons and the corresponding forms of reasoning. That somebody is smoking a joint may be a reason for the policeman to arrest him, though as a private person the bearer of this role may have no objection to it. So the policeman may reason deductively from his belief as a policeman that a certain man has smoked a joint and his (let us assume) general obligation as a policeman to arrest people who do such things, to the particular obligation to arrest this man.

It is necessary that this belief be one that the man holds as a policeman because if, for example, his personal belief was based on inadmissible evidence - say, obtained through illegal wiretapping - it could not provide a legally valid reason to arrest the man even if it was true. The general point here is that in our roles we have vantage points on the world that can differ from our merely personal, I-mode ones, both with regard to our practical and to our theoretical attitudes. Perhaps more obviously, we have special positive and negative practical powers, rights, duties and obligations, to do things. But we also may have what we could correspondingly call special theoretical, epistemic, positive and negative powers with regard to what is the case. That is, in our roles we may have access to otherwise inaccessible sources of evidence, but yet other 
sources may also be legally, institutionally inadmissible as in the policeman example. A case converse to that would be one where I have to accept something as true and act accordingly in my official capacity - say because it has been so determined by one of my superiors - even though personally I believe it to be false.

Many real life and fictitious dramas revolve around the kinds of conflict entailed by such divergences between our personal postures and those that we hold or are at least supposed to hold in our official capacities: the policeman who seeks admissible evidence to convict somebody whom he personally knows to be guilty; the whistleblower who turns against the official line of his or her organization. Nothing here is meant to downplay such conflicts. The claim is not that role postures and personal postures are completely shut off from one another in the minds of their bearers; quite the contrary. But it is still important to recognize the difference. If Angela Merkel holds a different view as leader of the CDU than as chancellor, this is certainly a potential source of conflict, but it won't be a plain contradiction, as it might be if she held both views in one role. And while too much divergence between personal and role attitudes is unhealthy, a certain degree of it is most likely unavoidable for society and organizations to function.

This is not the place for a full-scale argument for the claim that organizations or what Tuomela calls group agents can be accounted for in terms of role-mode. Let me just note a certain convergence between this line of thought and one that has recently been emphasized in social ontology, for example, by Searle, and which I think is also accepted by Tuomela, and then go on to argue that this shared observation is best explained in terms of role-mode conceived of as representational subject mode. The shared observation I have in mind is that social statuses and institutional facts are ultimately to be explained in terms of attributes of people. Social things such as dollar bills or pieces of properties are what they are because people have certain powers, rights and obligations with regard to them, or because, as in the former case, they indicate such powers, or are related in different ways to these and other attributes of people. Accordingly, a group agent such as a corporation is to be explained in terms of the powers - and as I have argued, also in terms of postures such as beliefs and plans - that people hold in their roles within the organization, as well as in terms of the positions that the officers of other actors in the broader institutional context of society - such as competitors, banks, and government agencies take in their roles. Now, I have already given some reasons why role is best understood in terms 
of role mode and why role mode is a subject mode: namely because role modifies the theoretical and practical vantage point of the role-bearer, his or her perceptual and actional apparatus with regard to the world. It gives the subject theoretical and practical access to certain things and restricts or blocks access to others, just like putting on glasses or using tools would. So this gives us a reason to think that it should be construed subjectively in the sense of Langacker introduced above.

This argument can be extended to apply to the relations between the functionaries of group agents. To accept the power structure of a group agent and to function in it is not merely to believe, for example, that a certain person is chairwoman of a corporation. That is, it is not sufficient to merely represent this as part of object content. Such a belief could be shared by any outsider, including archenemies of this company who consider it a fraud and deny it any legitimacy. Nor is it merely the fact that she has been appointed through a legally valid document. Though this is of course a very important fact, she cannot function as chairwoman if she is not accepted as such by her colleagues. To accept her authority means to accept that she has the power to make certain practical as well as theoretical determinations with regard to certain domains. She might say: "As chairwoman, I have determined that we are not selling enough in this market, and so I order you to take appropriate action." To accept this authority means to represent these domains from the vantage point of the role as her subordinate and thus as subject to the powers she has in her role. Finally, its functionaries will identify with a corporation or any organization to the extent that they experience their co-functionaries as cosubjects in pursuit of a common cause or purpose, in spite or even because of the fundamentally different roles they may have in this pursuit. If that is not the case anymore at all, we are dealing with a system of oppression rather a collective enterprise. Where to draw this line in particular cases can of course be a very hard question.

\section{Subject mode intentionality and the ontology of collective subjects}

Let me briefly review the main argument so far and then ask what progress we have made, respectively can make on the basis of that argument, with regard to what certainly is the most fundamental and difficult question for the theory of social ontology and collective intentionality, namely the existence and nature of collective subjects. Starting from the opposition between content, subject, and mode approaches to collective intentionality, the most fundamental question 
I asked about the SOCIAGA version of the we-mode approach was simply this: how is the wemode manifest in the mind? This innocent-sounding question turned out to be surprisingly hard to answer, particularly in a way that does not let the we-mode approach collapse into the content approach, as did one suggestion I made on Tuomela's behalf. So, in the spirit of a friendly suggestion to let the mode approach come into its own, I proposed to think of the we-mode as being representational and having content, but content of a special kind, mode content: attitude content that represents the position of a subject relative to some state of affairs represented by object content, and subject content that represents that individual or collective subject itself. I went on to argue that, if we recognize such content, we can also extend the we-mode approach to better deal with certain areas that are problematic on Tuomela's we-mode account. We can account for joint attention and other forms of sensory-motor-emotional intentionality below the level of application of notions of reasons and reasoning and deontological notions such as that of obligation, if we recognize non-conceptual forms of subject and position mode content: when we attend and act with others, we experience them as co-subjects rather than as objects, in an affectively charged sensory-motor-emotional way that displays the RAIMO-properties. I supplied some examples and data from developmental psychology to make vivid what that means concretely, how co-subjectivity is manifest in experience and action and to show how the concept of subject mode representation can explain certain findings. We-mode intentionality in the most fundamental sort of cases functions on the basis of sensory-motor-emotional connections, which it takes to the next level of joint intentions, beliefs and other postures. On that level also, the basic kind of we-mode intentionality is subject mode intentionality, where we represent the others as those we intend and believe things with, as co-subjects rather than as objects of our postures. On the level of organizational roles, the fundamental case which makes it possible for organizations to function is also the one where people represent each other as cosubjects with certain roles in pursuit of common causes and purposes. I also argued that on both latter levels, we can make better sense of how state of affairs can have the role of reasons, if we think of individual or collective subjects representing themselves and their positions, and, if applicable, the roles in which they take these positions.

So I suggested to adopt a viewpoint that tries to overcome the opposition between mode and content approaches in favor of the mode content account. Along the way I also already made some suggestions on how to make sense of collective subjects in this context, and I now want to 
make these suggestions fully explicit and take them a bit further. I want to argue that we can also bridge the divide between mode and subject approaches once we properly understand how mode representation is at least partially constitutive of collective subjects. But how can representation make what it is representing? Though many theorists of social ontology, notably Searle and Tuomela, have appealed to this idea in one form or another, it remains hard to understand. It is therefore no wonder that, as we noted earlier, SOCIAGA sometimes employs fictionalist language in this context, at least with regard to group agents. How could what individual subjects create by merely representing it be anything but a fiction? So Tuomela is led to the view that group agents are fictional creations of individuals that have extrinsic, derived intentionality only. But we also raised some doubts about it. In which sense are marriages and corporations supposed to be fictitious? It certainly seems that they don't belong to the realm of what we merely imagine or pretend to be the case, but are just part of reality. Nor, even though institutional reality in particular certainly involves a lot of derived intentionality - as it depends on legal statutes, contracts and many other forms of documentation - does institutional and collective intentionality more broadly appear merely derived across the board, as we discussed in our analysis of role intentionality. So how can we get out of this? I think the proposed account of role intentionality shows us a way of making sense of group agents without either opting for fictionalism or the collectivist Charybdis of the group agent as a separate person over and above the group members. We can agree that that idea is indeed a fiction - in the sense that it is simply false. And that certainly is an essential motivation for the SOCIAGA view of group agents, as many passages make clear. ${ }^{12}$ But Tuomela does feel compelled to throw out the babies of intrinsic group agent intentionality and the causal efficacy of this intentionality with the bathwater of this mistaken conception of the group agent. The account I have sketched avoids this by explaining group agents in terms of the role intentionality of the group members. That Apple has plans for the future just means that individuals have such plans in their roles as officers of the corporation. And this also means that they represent others as co-subjects of these plans in their respective roles - as superiors, subordinates, or equals in charge of certain areas.

${ }^{12}$ Compare e.g. p. 92 and the following passage on p. 223: "Fictitious" here means simply that the group mind ... of a group agent may appear to be real but actually is not, and the same in part goes for the group agent itself ... . However, if by a group agent's mind we mean only the collection of the group members' attitudes and mental states, no metaphysical quibbles about that should arise. 
Along these lines, I think we can even make sense of, ascriptions of feelings to Apple (see Schmid 2014b). I can't develop this account further here, but let me try at least to indicate how it and the subject mode account of collective intentionality more broadly may be able take the sting out of the idea that collectives can be created merely by representation.

Once again the root of our problem is the tendency to think that what we create or otherwise bring about through representation must be an object of the individuals' intentionality. If instead we think of what is being created through representation as the subject and its positions, we can find a way of making this thought more intelligible. Still of course no amount of just saying or thinking "we", "Apple", or "Austria" by itself will be sufficient to bring about the existence of collective subjects. But let us again look at some of the examples of this paper from the perspective of the creation of subjects. In experiencing somebody as a co-subject, as somebody who is like me in important respects, somebody who it is fun to share things with, who can be relied upon in dangerous situations, who I am drawn to act with jointly, I open up to this person and bond with her. I don't represent her as something that is the case, as an object of an objectifying theoretical posture, but as a co-subject of theoretical and practical positions. So through representation I become a different subject, a subject now tied to a co-subject of joint positions - if she experiences me in similar ways.

If such a sensory-motor-emotional tie is taken to the next level, as we imagined in the example of the couple that starts planning its walks, or even a future together, the bond becomes one of joint commitments and obligations. "Shall we go for a walk again tomorrow?", you ask, "Yes, let us!", I answer. In this way we take up a joint practical position by jointly representing it and its we-subject - us. And if this bond is deepened, we will negotiate further plans, but also values, beliefs, and a shared narrative in our interactions, representing various positions till we can jointly settle on them or agree to disagree. Again, the labor of representing collectivity is essentially a shared one, and we become a collective subject by jointly representing its positions. Finally, let us consider how in taking up an institutional, organizational role we need to grow into it. We need to learn to relate to the world from the practical and theoretical, agential and epistemic vantage point the role brings with it, and we need to relate to our co-subjects in pursuit of the purposes and the ethos of the organizations in terms of the social power relations attached to the role. We need to adapt to the role and, let us not forget, also to adapt the role to our individuality. We need to learn to say, with conviction “As [role] I tell you...". And again, the 
interpretation of the role will be established and negotiated in interactions, and again its representation is essentially a shared labor. I can only really be the occupant of the role and function as such if not only myself, but also my co-subjects, and other people in the broader institutional context, represent me in this way.

To put the argument in a nutshell, it seems to me that the sense of mystery surrounding collective subjects can be dispelled once we see: first, that they just consist of individuals as related in certain ways; second, that these relations are partially constituted through intentionality, through representation; third, that the kind of representation in question is mode representation of the subject and its position, where others are represented as co-subjects of practical and theoretical positions rather than as their objects; fourth, that we can take up positions jointly by representing them and thus jointly becoming the subjects we represent; fifth, that this process of becoming, growing into a collective subject essentially involves interaction, and at least on higher levels, also negotiation; sixth, that this labor of constitutively representing collectives is essentially a shared one.

Let me conclude this long paper by all too briefly addressing two aspects of the account of SOCIAGA that I have neglected so far even though they are quite central to it. The first is the distinction between the pro-group I-mode and the we-mode. Tuomela not only emphasizes that one can take a pro-stance towards a group without being in the outright we-mode, but he even holds that one can be in the I-mode when thinking we-thoughts and conversely. By contrast, I have only considered the we-mode and other modes as features of the representational structure of postures, of intentional states or speech acts, arguing that the subject position in that structure is of particular importance and the key to understanding collective intentionality. From this point of view I would assume that it does make a significant difference whether I take a positive stance towards a group from an I-perspective or outright identify with it in a we-thought. And I would also assume that Tuomela wouldn't disagree with this and would further also agree that the intentional structure of we-thoughts is important to understanding the we-mode. In turn, I would not want to deny that we can have a notion of mode as our measure of identification with a group that relates to an overall profile of attitudes rather than just to individual postures, so that by this measure my deification with a group might be low even though I would sometimes think corresponding we-thoughts. As I have emphasized, there will be a variety of collective attitudes on all the different levels, so that, for example, I might be working for a corporation and 
routinely taking positions in my role, while disagreeing with many of its values, often disagreeing with my co-workers, and showing only a very low degree of emotional identification with it. And of course I also don't disagree that collective postures often hang together in important ways, some of which Tuomela analyses in SOCIAGA. For these reasons, I suppose that this difference in our understanding of the notion of mode do not represent more than different foci within yet significantly overlapping theoretical interests.

The second point is connected to a real difference of opinon. Similarly to the Relational View of joint attention, and perhaps influenced by relational critiques of Searle's view such as those of Anthonie Meijers (2003) and Bernhard Schmid (2003), Tuomela holds that collective postures are conceptually group-based. This means that, for example, the we-intention of an individual depends on the others we-intending with him, so that, if only one of them abandons his or her intention, it "vanishes" (80) with it. In contrast, while I agree with Searle's critics that there are collective subjects, on my view this situation would only entail that the we-intention now misrepresents because the represented joint posture does not exist anymore. Collectivity does require relations between the relevant individuals, but these relations are intentional relations that obtain in virtue of representational states. These representational states can misrepresent like all forms of intentionality, but, as I have emphasized, they are special in that they can fail just because others do not also represent the same relation. So on the subject mode account the representational success of we-mode states, but not their existence, depends on the other group-members. I think it can also be argued that the existence-dependence claim raises the specter of the collectivist Charybdis that Tuomela is otherwise anxious to avoid, because it makes individual mental states dependent on a collective in a way that can't be explained through the causal interaction of individuals. This, it seems to me, is true even though the motivations for this view are often not the traditional collectivist ones, but are rather epistemological, normativist and broadly externalist. In any case, I hope to have shown how to be a robust realist about collective subjects while avoiding this consequence.

Of course much more could be said about all these points, but I must stop here. Raimo Tuomela has paved a path for a we-mode approach through the jungle of collective intentionality and meticulously developed it into a navigable road. I have joined him on his way, unbidden, walked a few steps with him, and now I am already making suggestions for the way ahead, based on a rather sketchy map. As he enjoys the joint pursuit of truth like the true philosopher he is, I 
think Raimo might still indulge me, at least by generously and gently pointing out where I have gone off course. ${ }^{13}$

\section{References}

Bermúdez, José Luis. 1998. The Paradox of Self-Consciousness. Cambridge, MA: MIT Press. Bratman, Michael E. 1992. "Shared Cooperative Activity." The Philosophical Review, 327-41. - 2014. Shared Agency: A Planning Theory of Acting Together. Oxford University Press. Campbell, John. 2002. Reference and Consciousness. Oxford: Clarendon Press.

Carpenter, Malinda, and Kristin Liebal. 2011. "Joint Attention, Communication, and Knowing Together in Infancy.” In Joint Attention: New Developments in Psychology, Philosphy of Mind, and Social Neuroscience, edited by Axel Seemann, 159-82.

Chartrand, Tanya L., and John A. Bargh. 1999. "The Chameleon Effect: The Perceptionbehavior Link and Social Interaction." Journal of Personality and Social Psychology 76 (6): 893.

Colman, Andrew M., Briony D. Pulford, and Jo Rose. 2008. "Collective Rationality in Interactive Decisions: Evidence for Team Reasoning." Acta Psychologica 128 (2): 38797.

Evans, Gareth. 1982. The Varieties of Reference. Oxford: Clarendon Press.

Gilbert, Margaret. 1992. On Social Facts. Princeton University Press.

Hakli, Raul, Kaarlo Miller, and Raimo Tuomela. 2010. "Two Kinds of We-Reasoning." Economics and Philosophy 26 (03): 291-320.

Hobson, Jessica, Ruth Harris, Rosa García-Pérez, and R. Peter Hobson. 2009. “Anticipatory Concern: A Study in Autism.” Developmental Science 12 (2): 249-63.

Hobson, R. Peter, and Jessica Hobson. 2011. "Joint Attention or Joint Engagement? Insights from Autism." In Joint Attention: New Developments in Psychology, Philosophy of Mind, and Social Neuroscience, edited by Axel Seemann, 115-36. Cambridge, MA: MIT Press.

Hobson, R. Peter, and Jessica A. Meyer. 2005. "Foundations for Self and Other: A Study in Autism.” Developmental Science 8 (6): 481-91.

Langacker, Ronald W. 1987. Foundations of Cognitive Grammar: Theoretical Prerequisites. Vol. I. Stanford University Press.

Liebal, Kristin, Tanya Behne, Malinda Carpenter, and Michael Tomasello. 2009. "Infants Use Shared Experience to Interpret Pointing Gestures.” Developmental Science 12 (2): 26471.

McGrath, Matthew. 2007. "Propositions." http://stanford.library.usyd.edu.au/entries/propositions/.

Meijers, Anthonie. 2003. “Can Collective Intentionality Be Individualized?” American Journal of Economics and Sociology 62 (1): 167-83.

Moll, Henrike, Malinda Carpenter, and Michael Tomasello. 2007. "Fourteen-Month-Olds Know What Others Experience Only in Joint Engagement." Developmental Science 10 (6): 826-35. doi:10.1111/j.1467-7687.2007.00615.x.

${ }^{13}$ Thanks to Olle Blomberg, Alessandro Salice, Alba Montes Sánchez, Glenda Satne, Hans Bernhard Schmid, Thomas Szanto, and Gerhard Thonhauser for a stimulating discussion of an earlier draft during a workshop in Vienna. 
Moll, Henrike, and Andrew N. Meltzoff. 2011. "Joint Attention as the Fundamental Basis of Understanding Perspectives." In Joint Attention: New Developments in Psychology, Philosophy of Mind, and Social Neuroscience, edited by Axel Seemann, 392-412. MIT Press.

Salice, Alessandro. 2014. "There Are No Primitive We-Intentions." Review of Philosophy and Psychology, 1-21.

Schiffer, Stephen R. 1972. Meaning. Oxford: Clarendon Press.

Schmid, Hans Bernhard. 2003. "Can Brains in Vats Think as a Team?" Philosophical Explorations 6 (3): 201-17. . 2009. Plural Action: Essays in Philosophy and Social Science. Springer. . 2014a. "Plural Self-Awareness." Phenomenology and the Cognitive Sciences 13 (1): 724. . 2014b. "The Feeling of Being a Group: Corporate Emotions and Collective Consciousness." Collective Emotions, 1.

Schmitz, Michael. forthcoming. "Joint Attention and Understanding Others." Synthesis Philosophica

- manuscript. "Mode Logic." edited by Neil Roughley and Julius Schälike. Mentis.

- 2012. "The Background as Intentional, Conscious, and Nonconceptual." In Knowing without Thinking: Mind, Action, Cognition and the Phenomenon of the Background, edited by Zdravko Radman, 57-82.

- 2013a. "Limits of Intention and the Representational Mind." In Acting Intentionally: Individuals, Groups, Institutions, edited by Gottfried Seebass, Michael Schmitz, and Peter M. Gollwitzer, 57-84. DeGruyter.

- 2013b. "Social Rules and the Social Background." In The Background of Social Reality, edited by Michael Schmitz, Beatrice Kobow, and Hans Bernhard Schmid, 107-25. Springer.

Schweikard, David P., and Hans Bernhard Schmid. 2012. "Collective Intentionality." In Stanford Encyclopedia of Philosophy, edited by Edward N. Zalta.

Searle, John R. 1983. Intentionality: An Essay in the Philosophy of Mind. Cambridge University Press.

- 1990. "Collective Intentions and Actions." Intentions in Communication 401: 401. 1995. The Construction of Social Reality. Simon and Schuster.

- 2010. Making the Social World: The Structure of Human Civilization. Oxford University Press.

Seemann, Axel. 2011. "Joint Attention: Toward a Relational Account." In Joint Attention: New Developments in Psychology, Philosophy of Mind, and Social Neuroscience, edited by Seemann, Axel, 183-202.

Sellars, Wilfrid. 1963. Imperatives, Intentions, and the Logic of "Ought." Wayne State University Press.

Tuomela, Raimo. 1995. “The Importance of Us: A Philosophical Study of Basic Social Notions.” http://philpapers.org/rec/TUOTIO.

—. 2002. The Philosophy of Social Practices: A Collective Acceptance View. Cambridge University Press. . 2007. The Philosophy of Sociality: The Shared Point of View. Oxford University Press. 
- 2013a. Social Ontology: Collective Intentionality and Group Agents. Oxford University Press.

- 2013b. "Who Is Afraid of Group Agents and Group Minds?" In The Background of Social Reality, 13-35. Springer.

Wilby, Michael. 2012. "Subject, Mode, and Content in 'We-Intention.'” Phenomenology \& Mind, no. 5: 94-106.

Wittgenstein, Ludwig. 1958. The Blue and Brown Books. Oxford: Blackwell. 